\title{
Social Participation Attenuates Decline in Perceptual Speed in Old and Very Old Age
}

\author{
Martin Lövdén \\ Max Planck Institute for Human Development
}

\author{
Paolo Ghisletta \\ University of Geneva
}

\author{
Ulman Lindenberger \\ Max Planck Institute for Human Development
}

\begin{abstract}
Does an engaged and active lifestyle in old age alleviate cognitive decline, does high cognitive functioning in old age increase the possibility of maintaining an engaged and active lifestyle, or both? The authors approach this conundrum by applying a structural equation model for testing dynamic hypotheses, the dual change score model (J. J. McArdle \& F. Hamagami, 2001), to 3-occasion longitudinal data from the Berlin Aging Study (Time 1: $n=516$, age range $=70-103$ years). Results reveal that within a bivariate system of perceptual speed and social participation, with age and sociobiographical status as covariates, prior scores of social participation influence subsequent changes in perceptual speed, while the opposite does not hold. Results support the hypothesis that an engaged and active lifestyle in old and very old age may alleviate decline in perceptual speed.
\end{abstract}

Keywords: engaged lifestyle, activity, cognition, old, dual change score model

Older individuals living an engaged and active life tend to perform better on tests of cognitive functioning than inactive individuals (e.g., T. Y. Arbuckle, Gold, \& Andres, 1986; Craik, Byrd, \& Swanson, 1987). Furthermore, changes in cognitive performance in old age have been reported to be weakly associated with changes in lifestyle factors, such as engagement in leisure activities (e.g., Mackinnon, Christensen, Hofer, Korten, \& Jorm, 2003) and intellectually stimulating activities (e.g., Hultsch, Hertzog, Small, \& Dixon, 1999). These findings are consistent with unidirectional, bidirectional, and third-variable accounts of the causal nexus between engaged lifestyle and cognition. In other words, the following questions remain to be answered: Does an active lifestyle in old age alleviate cognitive decline? Does high cognitive functioning facilitate maintenance of an engaged and active lifestyle? Is there evidence supporting both directions of causality? Or, is the association solely brought about by a shared set of antecedent conditions?

Though the general public and, to some extent, the medical community have embraced the notion that an engaged lifestyle

This study was conducted in the context of the Berlin Aging Study (BASE), which is cochaired by Paul B. Baltes and Karl Ulrich Mayer at the Max Planck Institute for Human Development, Berlin, Germany. We express our gratitude to all colleagues in BASE who contributed to the work reported here.

Correspondence concerning this article should be addressed to Martin Lövdén or Ulman Lindenberger, Center for Lifespan Psychology, Max Planck Institute for Human Development, Lentzeallée 94, D-14195, Berlin, Germany. E-mail: loevden@mpib-berlin.mpg.de or seklindenberger@ mpib-berlin.mpg.de, or to Paolo Ghisletta, Center for Interdisciplinary Gerontology, and Faculty of Psychology and Educational Sciences, University of Geneva, Route de Mon Idée 59, 1226 Thônex, Genève, Switzerland. E-mail: paolo.ghisletta@cig.unige.ch protects against cognitive decline, several studies have delivered mixed support and have underscored the conceptual (e.g., definition of engaged lifestyle) and methodological (e.g., time scale and direction of influence) difficulties involved in resolving this conundrum (e.g., Aartsen, Smits, van Tilburg, Knipscheer, \& Deeg, 2002; Hultsch et al., 1999; Mackinnon et al., 2003; Pushkar et al., 1999; Salthouse, Berish, \& Miles, 2002; Schaie, 1996; Schooler \& Mulatu, 2001). In this study, we take advantage of longitudinal data from the Berlin Aging Study (BASE; P. B. Baltes \& Mayer, 1999) and a structural equation model (SEM), the dual change score model (DCSM; McArdle, 2001; McArdle \& Hamagami, 2001; McArdle et al., 2004; see also Ghisletta \& Lindenberger, 2003), to examine dynamic links (i.e., state influencing change) between engaged lifestyle and cognition in old and very old age.

Intellectual development in adulthood and old age is multidimensional and multidirectional and is embedded in a complex system of biological and cultural influences that operate over multiple timescales (P. B. Baltes, Lindenberger, \& Staudinger, in press; Li, 2003; Lövdén \& Lindenberger, 2005). Both conceptually and methodologically, it is therefore important to consider the time scale on which interactions between engaged lifestyle and cognitive functioning may be operating. Concepts such as cognitive reserve (Stern, 2002) suggest that life experiences during earlier periods of the life span, such as educational and occupational attainment, and beneficial effects of these and other factors on cognitive functioning, contribute to resilience against late-life neurophysiological and cognitive decline. However, interactions may also operate over shorter time lags within given periods of life. The "disuse" hypothesis (see Salthouse, 1991, for an overview) proposes that changes in lifestyle during old age (e.g., retirement, loss of spouse, and subsequent social isolation) may result in reduced levels of mental stimulation and subsequent magnification of cognitive decline. Alternatively, but on a similar time scale, decline to 
low levels of cognitive functioning may lead to subsequent withdrawal from an active lifestyle. Finally, concurrent changes in cognitive performance and lifestyle may result from decline in general neurophysiological vitality, as well as from more closely coupled interactions between lifestyle and cognition. In this study, we focus on the hypotheses regarding relatively short (2-year) time-lagged influences operating in old and very old age. Thus, our findings are not pertinent to reciprocal influences between lifestyle and cognition that extend over longer periods of life (e.g., Schaie, 1996; Stern, 2002).

The lack of a clear taxonomy for individuals' interactions with the environment constitutes a challenge to this field of research that has resulted in both conceptual confusions and large variations in definitions of the engaged lifestyle construct (see Hertzog, Hultsch, \& Dixon, 1999; Hultsch et al., 1999; Pushkar et al., 1999, for discussion). Common operationalizations stem from narrowly defined constructs such as physical activity (see Churchill et al., 2002, for review) and intellectual stimulation (e.g., Salthouse et al., 2002), as well as from broader constructs such as leisure activity (e.g., Mackinnon et al., 2003) and environmental complexity (e.g., Schooler \& Mulatu, 2001). In this study, we define social participation as an individual's investment of physical and psychological resources into socially oriented activities of a sharing or instrumental kind (cf. Bukov, Maas, \& Lampert, 2002). Specifically, we operationalize this construct as the breadth of involvement and time invested in four broad categories of activities: instrumental activities beyond personal care activities, leisure activities, social activities, and work. Previous confirmatory factor analytic work in BASE (M. M. Baltes, Maas, Wilms, Borchelt, \& Little, 1999) has provided support for the validity of this construct (see Measures for details). Because we are primarily interested in dynamic influences and changes within old and very old age rather than in time-lagged effects over long periods of the life span, we use sociobiographical status (SBS) as a time-invariant covariate rather than as an indicator of an engaged lifestyle construct.

As a measure of cognitive performance, we selected perceptual speed. This was guided by two considerations. First, perceptual speed measures generally have superior psychometric properties (e.g., reliability) compared with other cognitive constructs (cf. Lindenberger, Mayr, \& Kliegl, 1993). This leads to more powerful modeling and more stable parameter estimates, especially in the context of longitudinal SEMs (Hertzog, Lindenberger, Ghisletta, \& von Oertzen, 2004). Second, perceptual speed is generally regarded as a powerful indicator of cognitive decline in adulthood and old age (Lindenberger et al., 1993; Salthouse, 1996; Verhaeghen \& Salthouse, 1997).

With respect to variables sampled and longitudinal design, this study is similar to previous relevant studies (e.g., Hultsch et al., 1999; Mackinnon et al., 2003). Its unique features are inclusion of the very old (age range at Time $1[\mathrm{t} 1]=70-103$ years) and the use of the DCSM (McArdle, 2001; McArdle \& Hamagami, 2001; McArdle et al., 2004). The DCSM relates to the cross-lagged correlations approach (Rogosa, 1980a, 1980b) and shares features with various SEM approaches that interpret correlations on the basis of two-occasion latent-difference scores (McArdle \& Nesselroade, 1994) or latent growth model (LGM; Bryk \& Raudenbush, 1987; Meredith \& Tisak, 1990) parameters. Using variants of these approaches, several longitudinal studies of the older population have approached the lifestyle-cognition interaction. For example, Bosma et al. (2002) found that level of leisure activity at baseline predicted changes (defined as difference scores) in perceptual speed, word fluency, and recall over a subsequent 3-year period. Because cognitive performance at baseline also predicted change in leisure activity, the authors postulated a reciprocal relationship (see also Schooler \& Mulatu, 2001). Albert et al. (1995) found that level of self-reported strenuous activity predicted cognitive performance 2 years later, independently of cognitive performance at baseline. Using a similar approach, Aartsen et al. (2002) found that perceptual speed at baseline predicted some aspects of activity level 6 years later, controlling for age, gender, education, and health. The various forms of activity at baseline, however, did not predict later cognitive performance. Mackinnon et al. (2003), using an LGM approach, found that level of leisure activity was positively associated with changes in episodic memory, whereas level of episodic memory was not significantly associated with changes in activity. However, on the basis of a broader set of analyses, the authors concluded that the results did not speak to the issue of causal direction.

In a related vein, several studies have found lower incidence of dementia among individuals participating in more physical and nonphysical activities at baseline, as well as among individuals with a larger social network at baseline (see Fratiglioni, PaillardBorg, \& Winblad, 2004, for review). Finally, using the latentdifference score model, Hultsch and colleagues (1999) reported that initial status of intellectually related activities (novel information processing) was positively associated with changes in working memory. With various model comparisons, however, Hultsch et al. highlighted that a model specifying changes in general cognitive functioning as predictive of decline in intellectual activity fitted as well as a model specifying that maintaining intellectual activities alleviates cognitive decline. Hultsch et al. concluded that the direction of influence was difficult to establish; that is, the results were equally consistent with the hypothesis that intellectual activity buffers against cognitive decline and the hypothesis that cognitive decline in old age begins to limit engagement in intellectual activities.

The multivariate DCSM offers several advantages over these related approaches. Of central importance, the DCSM estimates all parameters of an LGM but additionally allows the estimation of time-lagged relations among variables' states (actual scores on the variables at a given time point) and their reliable error-free portions of subsequent changes, simultaneously modeling their changes throughout the time series (i.e., state and change are not assumed time invariant, or static). Owing to these additional features, the model can be broadly regarded as belonging to the class of "dynamic" longitudinal models (see McArdle \& Hamagami, in press; Nesselroade, 2002, for overviews). Although no universal remedy, the DCSM also addresses several of the questionable properties of the cross-lagged correlations approach that have been a popular approach to address lead-lag hypotheses. That is, several problems inherent in the cross-lagged correlations approach are widely recognized (Rogosa, 1980a, 1980b). For example, crosslagged correlations do not routinely adjust for differential reliability and thus are biased toward assigning a stronger leading role to the variable with the highest reliability or strongest stability. In addition, the most frequently used underlying structural models rest on several strict and questionable assumptions of stationary processes, such as no change in variances and synchronous 
correlations over time. Thus, untenable assumptions cloud interpretation.

The DCSM, however, account for differential reliabilities and stabilities of the variables analyzed because the variables' error variances are estimated separately for the variables as well as simultaneously with the other parameters. Thus, the cross-domain dynamic effects are statistically controlled for reliability (hence, the model produces no bias toward assigning a stronger leading role to the variable with highest reliability or strongest stability). In addition, and as noted above, the DCSM does not assume stationary processes; rather, the model analyzes cross-lagged effects among the variables analyzed, while modeling their change (hence, it does not confound across-variables leading effects with within-variable change). Furthermore, the within-variable dynamic effects are partialed from the across-variables dynamic effects (hence, the model separates within-variable dynamic change effects from across-variables leading effects). As a consequence, the DCSM rests on fewer assumptions. In other words, the model does not assume equal reliability for the variables analyzed or stationary processes, nor that the within-variable dynamic effects are zero.

In the context of this study, a convenient feature of the DCSM is that it allows for empirical comparisons among models that formalize competing substantive hypotheses about the relation between engaged lifestyle and cognition. Specifically, hypotheses such as whether high levels of social participation in old age alleviate decline in perceptual speed can be rigorously evaluated by specifying the DCSM to address the following question: Does the influence of level of social participation on subsequent change in perceptual speed differ in magnitude from the influence of level of perceptual speed on subsequent change in social participation?

\section{Method}

The longitudinal design of BASE currently consists of five measurement occasions. During the first (Time 1; t1), third (Time 3; $\mathrm{t} 3$ ), and fourth (Time $4 ; \mathrm{t} 4)$ waves of assessment a wide variety of variables from various domains were administered. A select set of variables was assessed at the second (Time 2; t2) and fifth (Time 5; t5) waves. Adjacent assessment waves are separated by approximately 2 years. Here, we analyze data from $\mathrm{t} 1, \mathrm{t} 3$, and $\mathrm{t} 4$. Longitudinally, the sample size decreased from 516 at $\mathrm{t} 1$ to 206 at $\mathrm{t} 3$, and to 132 at $\mathrm{t} 4$. For extensive information concerning the design of BASE, detailed participant characteristics, detailed procedures, and the full battery of measures included, see P. B. Baltes and Mayer (1999). Only methodological features pertinent to the present study are described below.

\section{Participants}

The $\mathrm{t} 1$ sample (age range $=70-103$ years; $M=85.0, S D=8.7$ ) originated from random draws of addresses from the city registry of former West Berlin, stratified by age and gender, with 43 women and 43 men in each of six different age groups $(70-74,75-79,80-84,85-89,90-94$, and $95+$ years). Hierarchically nested selectivity analyses comparing the 516 individuals who were willing and able to complete the comprehensive $\mathrm{t} 1$ assessment with the total parent sample revealed that the 516 individuals were positively selected on a broad range of variables covering demographic, sensory/sensorimotor, life history, and intellectual domains (for details, see Lindenberger et al., 1999). However, with the exception of dementia prevalence, effect size estimates were well below 0.5 standard deviation. Thus, according to convention (Cohen, 1988), the positive mean selection can be regarded as small. Furthermore, variances and covariances were only marginally influenced by selectivity. Thus, the baseline sample was acceptably representative of the target population.
Longitudinal mean selectivity on the variables included in this study can be expressed in an effect-size metric, indicating the magnitude to which individuals that survived and participated in $\mathrm{t} 4$ differed from their parent sample at $\mathrm{t} 1$ (for $\mathrm{t} 3$ information and relevant statistical procedures, see Lindenberger, Singer, \& Baltes, 2002). Total selectivity at t4 for measures assessed at $\mathrm{t} 1$ amounted to 0.70 standard deviation units for perceptual speed, 0.73 standard deviation for social participation, 0.28 standard deviation for SBS, and 0.76 standard deviation for chronological age. As is true for other longitudinal SEM techniques using full information maximum likelihood (FIML) estimation, the DSCM takes this form of nonrandom attrition into account (see Statistical Procedures).

\section{Measures}

Perceptual speed (Speed). Two tests, Digit Letter and Identical Pictures, formed a unit-weighted composite measure called Speed. The t1 composite was scaled to the T metric $(M=50, S D=10)$, and the $\mathrm{t} 3$ and $\mathrm{t} 4$ composites were scaled using the means and standard deviations from $\mathrm{t} 1$ as reference values.

The Digit Letter test resembles the well-known Digit Symbol Substitution task of the Wechsler Adult Intelligence Scale, with the exception that participants named letters instead of writing symbols. The test consisted of a total of 21 sheets, each sheet containing six digits with a question mark underneath. A template with digit-letter pairings was visible during the testing period. Participants named the letters corresponding to the digits, by moving from left to right. The dependent measure was the number of correct responses after $3 \mathrm{~min}$. The reliability at $\mathrm{t} 1$ of this test is very high (Cronbach's $\alpha=.96$ ).

The Identical Pictures test is a computerized and modified version of the corresponding test from the Educational Testing Service (Ekstrom, French, Harman, \& Derman, 1976). A Macintosh SE30 computer equipped with a touch-sensitive screen was used to present a total of 32 items. For each item, a target picture was presented in the upper half of the screen, and five response alternatives were presented in the lower half. Participants were to touch the picture in the lower half of the screen that corresponded to the target picture. The dependent measure was the number of correct responses within $80 \mathrm{~s}$. The reliability at $\mathrm{t} 1$ of this measure is high $(\alpha=.90)$.

Social participation (Social). Two instruments, the Yesterday Interview (Moss \& Lawton, 1982) and Activity List, generated one measure each of social participation. The Yesterday Interview is a semistructured interview that attempts a minute-to-minute reconstruction of the activities in which the individual engaged during the day preceding the interview. This reconstruction enables assessment of type, frequency, duration, and context (e.g., presence of social partners) of the activities. The dependent measure derived from this instrument was defined as the total time (minutes) spent engaged in leisure activities (e.g., attending cultural events), instrumental activities beyond personal care (e.g., banking), social activities (e.g., visiting people), and work (e.g., regular paid work). Interrater reliability for the codings of the activities is quite high $(\kappa$-scores $>0.80)$.

The Activity List was used in the BASE as part of a sociological interview containing a detailed life history and life situation questionnaire (see Mayer, Maas, \& Wagner, 1999, for a detailed description). To further the knowledge on activities accomplished outside their private domain, participants were shown cards, each illustrating a category of activities, and were asked whether they had engaged in activities of that kind during the past 12 months. ${ }^{1}$ The categories of activities were as follows: sports, restaurant visits, dancing, day trips, attending cultural events, hobbies, volunteer work, traveling, creative activities, playing games, continuing

\footnotetext{
${ }^{1}$ Because the retrospective nature of this variable might have biased the analyses toward finding a time-lagged effect of social participation on perceptual speed, we also ran the models with only the Yesterday Interview as an indicator of social participation. These analyses yielded substantively identical results to those reported here.
} 
education, and political activities. The number of categories of activities in which participants reported at least one activity was the dependent measure derived from this instrument.

The two measures were used to form a unit-weighted composite measure, Social, that was scaled to the T metric analogous to that of Speed. For detailed confirmatory factor analytic background on this construct, see M. M. Baltes et al. (1999). Only a brief description of this work is provided here. Confirmatory factor modeling provided support for the independence of the social participation construct (indexed by the measure from the Yesterday Interview and the measure from the Activity List) in relation to other constructs such as fluid intelligence, personality (indexed by extraversion, openness to experience, and life investment), and balance/gait. In a structural model, the standardized paths from fluid intelligence (0.48), personality (0.25), and balance/gait (0.40) to the social participation factor were significant. This should be compared with the paths to a basic competence factor, indexed by Activities of Daily Living (Katz, Ford, Moskowitz, Jackson, \& Jaffe, 1963) and Instrumental Activities of Daily Living (Lawton \& Brody, 1969), which were only significant for balance/ gait $(0.90)$ and depressivity $(0.10)$. In other words, the social participation factor was found to be more closely related to psychosocial variables and less closely associated with health-related variables, compared with the basic competence construct. In addition, the social participation construct contained age-related variance not explained by the Activities of Daily Living scale. Thus, the convergent and discriminant validity of the construct appear to be good.

SBS. The following four variables formed a unit-weighted composite representing SBS (cf. Mayer et al., 1999): (a) income, defined as the amount of net income per month on a 5-point scale; (b) occupational prestige, based on a standard sociological measure for Germany; (c) social class; and (d) number of years of formal education.

\section{Statistical Procedures}

For in-depth description of the DCSM and its underlying assumptions we refer to recent extensive treatments by McArdle and colleagues (e.g., McArdle, 2001; McArdle \& Hamagami, 2001; McArdle et al., 2004) and by Ghisletta and Lindenberger (2003). Here, we restrict the discussion to conveying the fundamental properties of the DCSM by taking the related but more commonly used LGM (Bryk \& Raudenbush, 1987; Meredith \& Tisak, 1990) as a starting point.

Figure 1 displays the graphical representation of a univariate DCSM as we implement it here. Unlabeled paths in this figure are fixed to 1 . In this representation we assume error-free values of $x[\mathrm{t}]$, where $\mathrm{t}$ equals time of assessment, with 2 years between each possible measurement (i.e., $x[1]$, $x[2], x[3], x[4])$, although the observed variables $X[\mathrm{t}]$ were only measured at three occasions (t1, t $3, \mathrm{t} 4)$. This equal-interval approach greatly simplifies estimation and interpretation-and guarantees the invariant time scaling of all parameters. The latent scores $x[\mathrm{t}]$ are defined as the unit-weighted sum of the latent score at $x[\mathrm{t}-1]$ plus the latent change score $\Delta x[\mathrm{t}]$, so that $\Delta x[\mathrm{t}]$ is interpreted as the latent difference score (reliable change) between $x[\mathrm{t}-1]$ and $x[\mathrm{t}]$ (McArdle \& Nesselroade, 1994). The separately estimated error variance $\sigma_{\mathrm{e}}^{2}$ is commonly assumed to neither correlate with itself nor change over time. Two latent variables, the intercept $x_{0}$ and the linear slope $X_{\mathrm{s}}$, are proposed to account for the time series information. The intercept $x_{0}$ represents an individual's latent score at the beginning of the time series (i.e., at $x[1]$ ), and the slope $X_{\mathrm{s}}$ represents the time-invariant portion of an individual's 2-year change scores. The slope $X_{\mathrm{s}}$ represents linear change because it is related with a constant loading of 1 to the difference scores $\Delta x[\mathrm{t}]$. Both the intercept $x_{0}$ and slope $X_{\mathrm{s}}$ factors are estimated at the population level (i.e., their means $\mu_{0}$ and $\mu_{\mathrm{s}}$ are estimated), they both allow for interindividual differences (i.e., their variances $\sigma_{0}^{2}$ and $\sigma_{\mathrm{s}}^{2}$ are estimated), and they may covary $\rho_{0 \mathrm{~s}}$.

Estimating the six parameters mentioned so far $\left(\mu_{0}, \mu_{\mathrm{s}}, \sigma_{0}^{2}, \sigma_{\mathrm{s}}^{2}, \rho_{0 \mathrm{~s}}\right.$, $\sigma_{\mathrm{e}}^{2}$ ) corresponds to estimating a classic linear LGM. The DCSM, however,

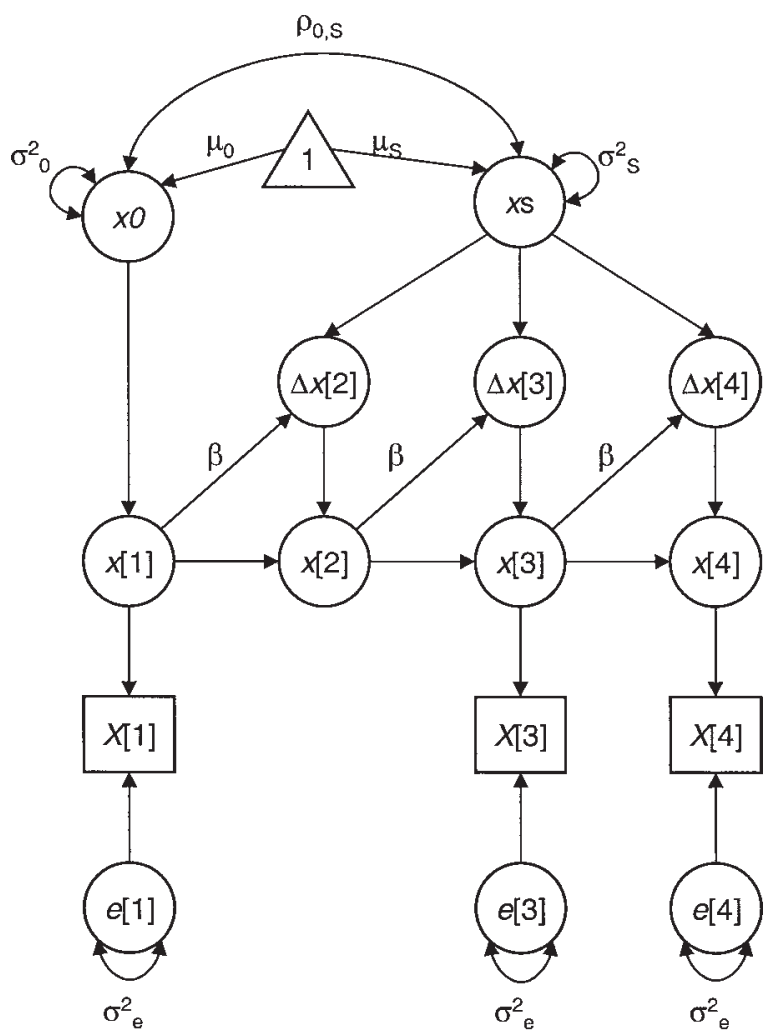

Figure 1. Graphical representation of a univariate dual change score model (McArdle, 2001; McArdle \& Hamagami, 2001) estimating seven parameters. All unlabeled parameters are fixed to 1. Manifest (i.e., observed) variables are represented by squares, latent variables (e.g., factors) by circles, regression weights by one-headed arrows, variance and covariances by two-headed arrows, and the triangle is used to indicate means and intercepts.

additionally allows for estimation of an autoproportion parameter, $\beta$, which denotes the effects of an individual's score at $x[\mathrm{t}-1]$ on an individual's subsequent change between $x[\mathrm{t}-1]$ and $x[\mathrm{t}]$. This additional parameter represents a second effect, in addition to the linear slope, on the latent change score $\Delta x[\mathrm{t}]$. The major novelty of the DCSM consists in defining the latent change scores $\Delta x[\mathrm{t}]$ as the sum of the linear slope $X_{\mathrm{s}}$ and the autoproportion effect $\beta$ of the previous measurement $x[\mathrm{t}-1]$. In the regular LGM, the latent change scores $\Delta x[t]$ are implicitly assumed to be solely the function of the linear slope $X_{\mathrm{s}}$. For simplicity, the $\beta$ s are commonly assumed to be of the same magnitude across occasions of measurement, although this is a testable assumption. ${ }^{2}$ With $\beta$ set to 0 , the DCSM is equivalent to a linear LGM.

As with the LGM, multivariate extensions of the DCSM are possible. A bivariate LGM would estimate 2 times the six parameters of each time series plus four covariances among the intercepts and slopes (i.e., a total 16 parameters). The bivariate DCSM (BDCSM) extends the bivariate LGM by estimating four additional parameters: the two autoproportion $\beta$ s and, analogous to these, two intervariable cross-lagged parameters, called $\gamma$, representing the effect that a variable at time $t-1$ exerts on the change of the other variable between times $t-1$ and $t$. Our main empirical interest

\footnotetext{
${ }^{2}$ In the present application, various model alternatives involving a relaxation of this constraint did not produce any improvements in fit (all $p s>.22)$.
} 


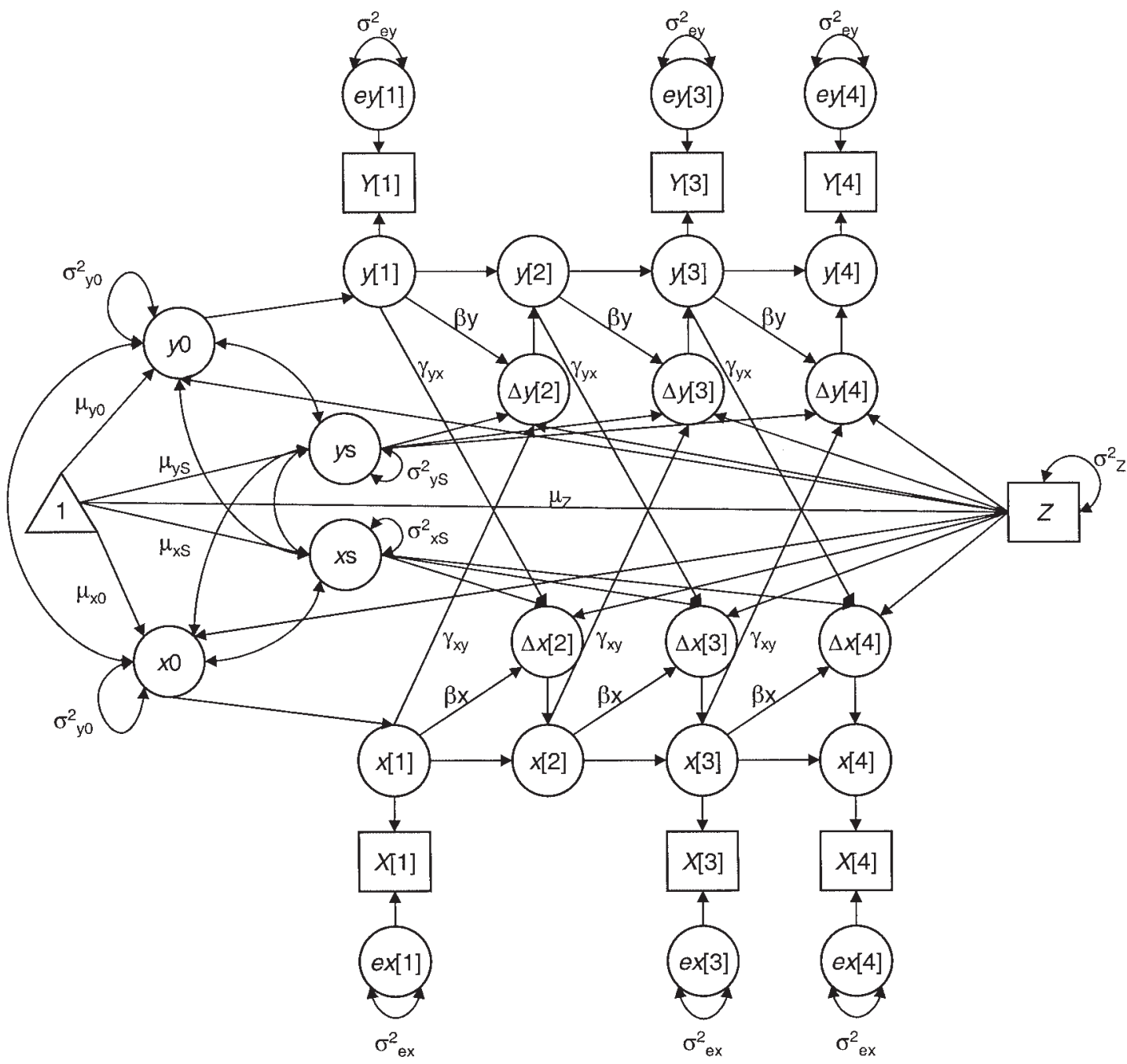

Figure 2. Graphical representation of a bivariate dual change score model with one covariate (McArdle, 2001; McArdle \& Hamagami, 2001) estimating 26 parameters. All unlabeled parameters, with exception of the estimated correlations and regression paths from the covariate $Z$, are fixed to 1 . Manifest (i.e., observed) variables are represented by squares, latent variables (e.g., factors) by circles, regression weights by one-headed arrows, variance and covariances by two-headed arrows, and the triangle is used to indicate means and intercepts.

is in these cross-lagged $\gamma$ parameters, or coupling effects; that is, we are interested in the dynamic effects of state of perceptual speed on subsequent latent change in social participation (i.e., $\gamma_{\text {Speed-Social }}$ ) and of state of social participation on latent change in perceptual speed (i.e., $\gamma_{\text {Social-Speed }}$ ).

Figure 2 displays graphically a BDCSM that includes a time-invariant covariate $Z$. The covariate $Z$ is implemented as influencing the latent intercept factors $x_{0}$ and $y_{0}$ and the latent-difference scores $\Delta x[\mathrm{t}]$ and $\Delta y[\mathrm{t}]$. For simplicity, it is assumed that the effects of the covariate on the latent-difference scores are equal over time, although this is an empirical, and testable, assumption. ${ }^{3}$ In addition to the 20 parameters estimated by the BDCSM, this model also estimates the mean and variance of $Z$, the two regression effects of $Z$ on the intercepts, and the two regression effects of $Z$ on the difference scores. This model thus estimates 26 parameters. In this study, we include two covariates in the estimated models: chronological age and SBS. Thus, the two coupling parameters $\gamma_{\text {Social-Speed }}$ and $\gamma_{\text {Speed-Social }}$ are residualized for linear effects of age, SBS, and the autoproportion $\beta \mathrm{s}$. This model estimates 33 parameters, that is, the 26 parameters portrayed in Figure 2 plus the six parameters for a second covariate and a covariance term between age and SBS.
We used AMOS 5.0 (J. L. Arbuckle \& Wothke, 1999) for all computations ${ }^{4}$ and used FIML (see J. L. Arbuckle, 1996; Wothke, 2000, for overviews), which accommodates incomplete data by using all available data points (no participants are excluded and no incomplete data are imputed) and adjusts for longitudinal selectivity under the assumption that data are missing at random (Rubin, 1974). This assumption allows for differences in level of performance and observed change to predict future participation. The FIML algorithm as applied here is enhanced by the inclusion of variables that have been shown to be strong predictors of experimental and mortality-associated dropout in this data set (i.e., SBS,

\footnotetext{
${ }^{3}$ In the present application, various model alternatives involving a relaxation of this constraint did not produce any improvements in fit (all $p \mathrm{~s}>.28)$

${ }^{4}$ Computations with Mx (Neale, Boker, Xie, \& Maes, 1999) produced identical results (within rounding errors) to those reported here.
} 
age, social participation, and perceptual speed; see Lindenberger et al., 2002). ${ }^{5}$

Substantively alternative models were specified as restrictions of the full BDCSM with age and SBS as covariates. Hence, the competing hypotheses could be assessed by comparing statistically nested models. Specifically, we estimated five alternative versions of the BDCSM of perceptual speed and social participation, with chronological age and SBS as covariates. The first model, labeled full coupling, postulates that both social participation and perceptual speed are dynamically active in the system considered. In this model, both cross-lagged $\gamma$ parameters are estimated. This model is the least parsimonious of the five models that we estimated, and the following four models are statistically nested within it. In the second model, labeled coupling $\gamma_{\text {Speed-Social }}=0$, the coupling $\gamma_{\text {Speed-Social }}$ is fixed at 0 while the coupling $\gamma_{\text {Social-Speed }}$ is estimated. A significant loss in goodness of fit for this model compared with the full coupling model corresponds to not being able to reject the hypothesis that perceptual speed is leading change in social participation. In the third model, labeled coupling $\gamma_{\text {Social-Speed }}=0$, the coupling $\gamma_{\text {Social-Speed }}$ is fixed at 0 while the coupling $\gamma_{\text {Speed-Social }}$ is estimated. A significant loss in goodness-of-fit for this model compared with the full coupling model means that one cannot reject the hypothesis that social participation is leading change in perceptual speed. In the fourth model, called equal coupling, the two $\gamma$ parameters are postulated to be equal. Though potentially plagued by scaling differences, statistically rejecting this model, assuming that the full coupling model is correct, means that one cannot reject the hypothesis that the two $\gamma$ parameters are of unequal magnitude. Finally, in the fifth model, no coupling, both $\gamma_{\text {Social-Speed }}$ and $\gamma_{\text {Speed-Social }}$ are fixed at 0 . Statistically rejecting this model, under the assumption that the model full coupling is correct, means that one cannot reject the hypothesis that there are coupling effects between the two variables.

The alpha level for all statistical decisions was set at .05 and the difference in chi-square fit statistics was used to compare nested models. To complement this test we computed the comparative root-mean-square error of approximation (CRMSEA; Browne \& DuToit, 1992). The CRMSEA takes into account the chi-square value, sample size, and model parsimony and is computed by applying the usual root-mean-square error of approximation (RMSEA) formula to the chi-square difference statistics and its relative difference in degrees of freedom ( $d f \mathrm{~s}$; Steiger \& Lind, 1980, as cited in Browne \& Cudeck, 1993). When comparing two nested models, a CRMSEA of 0 means that there is no significant difference between the fits of the two models. Values of .05 or below are interpreted as indicating almost no statistical difference, and values above .05 are interpreted as indicating statistical difference. Model fit was evaluated with the following fit indices: $\chi^{2} / d f$, comparative fit index, Browne-Cudeck criterion (BCC), and RMSEA. A $\chi^{2} / d f$ below 2, a comparative fit index above .95 , and a RMSEA below .05 indicate acceptably fitting models. Lower values of the BCC indicate better fitting models. Kline (1998) can be consulted for more details on these indices.

\section{Results}

Descriptive statistics for the observed variables are summarized in Table 1. As evident from this table, all variables have acceptable skewness and kurtosis values. The 33 parameter estimates and their standard errors from the full coupling model are summarized in Tables 2 and 3. Table 2 shows the estimates of the parameters that are mirrored between the measures for Speed and Social. Table 3 displays the estimates of the parameters that are added to the model by the bivariate application (BDCSM). Several estimates in these tables are of interest.

First, Table 2 shows that age has a significant negative and SBS has a significant positive unique relation to both level of social participation and level of perceptual speed. However, neither co-
Table 1

Descriptive Statistics for Variables Used in the Structural Equation Models

\begin{tabular}{lrrrrr}
\hline \multicolumn{1}{c}{ Variable } & $n$ & $M$ & $S D$ & Skewness & Kurtosis \\
\hline Age (t1) & 516 & 85.04 & 8.68 & 0.03 & -1.15 \\
SBS (t1) & 516 & 50.00 & 10.00 & 0.56 & 0.13 \\
Perceptual speed (t1) & 440 & 50.00 & 10.00 & -0.30 & -0.57 \\
Perceptual speed (t3) & 176 & 53.73 & 9.47 & -0.78 & 0.19 \\
Perceptual speed (t4) & 120 & 54.53 & 9.40 & -0.76 & 0.99 \\
Social participation (t1) & 516 & 50.00 & 10.00 & -0.34 & -0.38 \\
Social participation (t3) & 206 & 52.43 & 8.83 & -0.52 & 0.55 \\
Social participation (t4) & 132 & 52.98 & 7.54 & -0.75 & 0.89 \\
\hline
\end{tabular}

Note. $\mathrm{t} 1=$ Time $1 ; \mathrm{SBS}=$ Sociobiographical Status; $\mathrm{t} 3=$ Time $3 ; \mathrm{t} 4=$ Time 4.

variate exerts significant influences on the latent-difference scores (i.e., on change).

Second, an inspection of Table 2 reveals that the autoproportion parameter $\beta$ was significantly negative for Speed but nonsignificantly positive for Social. To avoid the risk of biasing the substantively most interesting estimates (i.e., the $\gamma \mathrm{s}$ ), we decided to retain the nonsignificant $\beta$ parameter in the overall modeling procedure.

Third, we note that it is difficult to interpret directly the means for the slopes that are displayed in Table 2 because they represent only one component of change and need to be interpreted in conjunction with the remaining change components (i.e., the autoproportion effect, the coupling effect, the effect of age, and the effect of SBS). Therefore, the model-implied mean longitudinal trajectories are displayed in Figure 3. The implied means for $x[\mathrm{t}]$ $>x[1]$ are produced by the following formula: $x[\mathrm{t}]=1 \times X_{\mathrm{s}}+$ $(1+\beta x) \times x[\mathrm{t}-1]+\gamma_{\mathrm{y}-\mathrm{x}} \times y[\mathrm{t}-1]$, when applied for a person of average age and average SBS. For $x[1]$ the mean equals $x_{0}$. When inspecting Figure 3 it should be noted that the implied intercept of perceptual speed is lower than the T-scaled t 1 mean of 50 because the participants not providing perceptual speed data at t1 $(n=76)$ are expected to perform lower than the participants providing data at $\mathrm{t} 1(n=440) .{ }^{6}$ As noted before, the FIML algorithm takes the information of the other variables in the model into account to provide the expectations. Note also the dramatic difference between the time-related decreases in the means portrayed in Figure 3 and the time-related increases in the observed means provided in Table 1 . The means in Table 1 increase mainly because the sample is becoming more select as a function of time. Here, the FIML algorithm separates within-person change from predictable selective attrition, thereby allowing for more realistic estimates of mean changes in the overall sample.

Fourth, we note that Table 2 reports that the variances for the linear slopes are positive but nonsignificant for both Speed and Social. The estimation of the $\gamma$ parameters does not necessitate

\footnotetext{
${ }^{5}$ Analyses restricted to participants taking part in $\mathrm{t} 4$ and providing social participation data $\left(n=132\right.$; age range t $_{1}=70-100$ years; $M=78.4$ ) yielded substantively identical results to those reported here.

${ }^{6}$ Analyses restricted to data from participants providing perceptual speed data at $\mathrm{t} 1(n=440)$ yielded substantively identical results to those reported here.
} 
Table 2

BDCSM (Full Coupling) Results for Social Participation (Social) and Perceptual Speed (Speed), Including Age and Sociobiographical Status (SBS) as Covariates

\begin{tabular}{lccccc}
\hline & \multicolumn{2}{c}{ Speed } & & \multicolumn{2}{c}{ Social } \\
\cline { 2 - 3 } \cline { 6 - 7 } \multicolumn{1}{c}{ Parameter } & Estimate & $S E$ & & Estimate & $S E$ \\
\hline Proportion $\beta$ & $-0.69^{*}$ & 0.28 & & 0.42 & 0.61 \\
Initial mean $\left(\mu_{\mathrm{o}}\right)$ & $49.02^{*}$ & 0.36 & & $50.02^{*}$ & 0.34 \\
Slope mean $\left(\mu_{\mathrm{s}}\right)$ & -20.13 & 11.27 & & -13.73 & 16.17 \\
Initial variance $\left(\sigma_{0}^{2}\right)$ & $51.29^{*}$ & 4.12 & & $37.59^{*}$ & 4.00 \\
Slope variance $\left(\sigma_{\mathrm{s}}^{2}\right)$ & 36.55 & 26.72 & & 4.98 & 13.87 \\
Error variance $\left(\sigma_{\mathrm{e}}^{2}\right)$ & $7.71^{2}$ & 1.11 & & $22.30^{*}$ & 2.06 \\
Age $\Rightarrow$ Level & $-0.67^{*}$ & 0.04 & & $-0.61^{*}$ & 0.04 \\
Age $\Rightarrow \Delta[\mathrm{t}]$ & 0.01 & 0.14 & & 0.08 & 0.19 \\
SBS $\Rightarrow$ Level & $0.30^{*}$ & 0.04 & & $0.29^{*}$ & 0.03 \\
SBS $\Rightarrow \Delta[\mathrm{t}]$ & -0.12 & 0.08 & & -0.08 & 0.10 \\
\hline
\end{tabular}

Note. All estimates are unstandardized. BDCSM $=$ bivariate dual change score model.

$* p<.05$

variances in the linear slopes, but the data analyzed must be longitudinal, otherwise the model is not fully identified, yielding a nonrejectable solution (see Ghisletta \& Lindenberger, 2003, for details). However, restrictions in variance are probably contributing to the unstable estimates of the covariances that involve the slope factors. That is, these correlations are very high, but the underlying covariances are not significant because their standard errors are improperly large. Thus, these estimates should be interpreted with caution. Note, however, that other parameter estimates (e.g., the coupling parameters) are not affected by unstable estimates at the level of the covariances (see also Ghisletta \& Lin-

Table 3

Parameter Estimates From the BDCSM (Full Coupling) of Social Participation (Social) and Perceptual Speed (Speed), With Age and Sociobiographical Status (SBS) as Covariates

\begin{tabular}{ccc}
\hline Parameter & Estimate & $S E$ \\
\hline Coupling $\gamma_{\text {Speed-Social }}$ & -0.18 & 0.38 \\
Coupling $\gamma_{\text {Social-Speed }}$ & $1.04^{*}$ & 0.44 \\
Mean age $\left(\mu_{\text {AGE }}\right)$ & $0.00^{\mathrm{a}}$ & 0.38 \\
Mean SBS $\left(\mu_{\text {SBS }}\right)$ & $0.00^{\mathrm{a}}$ & 0.44 \\
Age variance $\left(\sigma_{\mathrm{AGE}}^{2}\right)$ & $75.11^{*}$ & 4.68 \\
SBS variance $\left(\sigma_{\mathrm{SBS}}^{2}\right)$ & $99.81^{*}$ & 6.22 \\
$\rho_{\text {AGE,SBS }}$ & $-.09^{*}$ & \\
$\rho_{\text {Socialo,Socials }}$ & -.83 & \\
$\rho_{\text {Speed0,SpeedS }}$ & .28 & \\
$\rho_{\text {Speed0,Socials }}$ & -.05 & \\
$\rho_{\text {Social0,SpeedS }}$ & -.54 & \\
$\rho_{\text {Social0,Speed0 }}$ & $.54^{*}$ & \\
$\rho_{\text {SocialS,SpeedS }}$ & .94 & \\
\hline
\end{tabular}

Note. All noncorrelation estimates are unstandardized. The significance tests assigned to the correlations refer to the corresponding covariances. BDCSM = bivariate dual change score model; Social0 = initial level of social participation; SocialS = linear slope for social participation; Speed0 = initial level of perceptual speed; SpeedS = linear slope for perceptual speed.

age and SBS were centered at zero.

$* p<.05$.

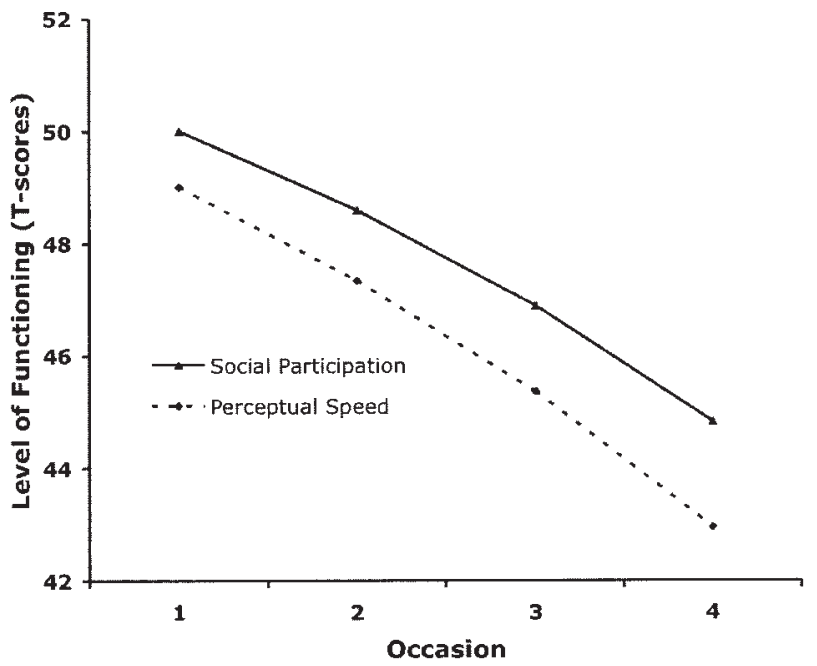

Figure 3. Model implied means for social participation (thick line) and perceptual speed (dashed line) from the bivariate dual change score model (full coupling) for a hypothetical person with sample average age and sociobiographical status.

denberger, 2003; Hamagami \& McArdle, 2001; McArdle et al., 2004). Moreover, the correlations are not straightforward to interpret because they are products of quite complex expectations. As outlined in the Statistical Procedures section, fixing the $\beta$ and $\gamma$ parameters to 0 corresponds to a linear bivariate LGM, which provide estimates that are more directly comparable to previously reported empirical results concerning the engaged lifestylecognition association in old age (e.g., Hultsch et al., 1999; Mackinnon et al., 2003). Consistent with some findings reported in these previous studies, the correlation in a linear bivariate LGM among the levels of social participation and perceptual speed (.53) as well as the correlation between the slopes (.58) were significant and positive.

Finally, Table 3 shows that the coupling parameter $\gamma_{\text {Social-Speed }}$ is positive and significant, whereas the coupling parameter $\gamma_{\text {Speed-Social }}$ is slightly negative but nonsignificant. Thus, these estimates appear indicative of a bivariate system in which previous scores of Social are modifying subsequent changes in Speed, but the opposite does not hold. Specifically, the positive and significant coupling parameter $\gamma_{\text {Social-speed }}$ indicates that higher levels of social participation precede and predict 2-year positive deviations from the mean linear slope while the influences of the autoproportion parameter $\beta$ and the influences of the covariates are taken into account. However, this is not the case for the effect of level of perceptual speed on subsequent 2-year changes in social participation.

The goodness-of-fit indices for the full coupling model and its alternatives, as well as model comparisons, are summarized in Table 4 . These results are consistent with the significant nature of the $\gamma_{\text {Social-Speed }}$ estimate and the nonsignificant $\gamma_{\text {Speed-Social }}$ estimate from the full coupling model. Specifically, not allowing for a lagged influence from Social onto changes in Speed (i.e., coupling $\gamma_{\text {Social-Speed }}=0$ ) resulted in a highly significant loss in fit, $\Delta \chi^{2}(1, N=516)=8.44$; CRMSEA $=0.120$, relative to the full coupling model. In comparison, not allowing for a lagged influ- 
Table 4

Goodness-of-Fit Model Comparison Among Alternative Bivariate Models of Social Participation (Social) and Perceptual Speed (Speed), Including Age and Sociobiographical Status as Covariates

\begin{tabular}{|c|c|c|c|c|c|c|c|c|}
\hline \multirow[b]{2}{*}{ Model } & \multicolumn{8}{|c|}{ Goodness-of-fit indices } \\
\hline & $\chi^{2}$ & $(d f)$ & RMSEA & $\mathrm{BCC}$ & CFI & $\Delta \chi^{2}$ & $(d f)$ & CRMSEA \\
\hline Full coupling & 9.68 & (11) & 0.000 & 76.86 & 1.000 & - & - & - \\
\hline Coupling $\gamma_{\text {Speed-Social }}=0$ & 9.91 & (12) & 0.000 & 75.05 & 1.000 & 0.23 & (1) & 0.000 \\
\hline Coupling $\gamma_{\text {Social-Speed }}=0$ & 18.12 & (12) & 0.032 & 83.26 & 0.995 & 8.44 & $(1)^{\mathrm{a}}$ & 0.120 \\
\hline $\begin{array}{l}\text { Equal coupling } \\
\text {. Spect }\end{array}$ & 15.14 & (12) & 0.026 & 80.28 & 0.997 & 5.46 & $(1)^{\mathrm{a}}$ & 0.093 \\
\hline No coupling & 18.23 & (13) & 0.028 & 81.33 & 0.995 & 8.54 & $(2)^{a}$ & 0.121 \\
\hline
\end{tabular}

Note. $\quad$ RMSEA $=$ root-mean-square error of approximation; $\mathrm{BCC}=$ Browne-Cudeck criterion; CFI $=$ comparative fit index; CRMSEA = comparative root-mean-square error of approximation.

a Significant loss $(p<.05)$ in chi-square assuming the full coupling model to be correct.

ence from perceptual speed onto changes in social participation (i.e., coupling $\gamma_{\text {Speed-Social }}=0$ ) was associated with a virtually zero loss in fit, $\Delta \chi^{2}(1, N=516)=0.23$; CRMSEA $=0.000$, relative to the full coupling model. In addition, we can neither accept the equal coupling model, $\Delta \chi^{2}(1, N=516)=5.46$; CRMSEA $=0.093$, nor the no coupling model, $\Delta \chi^{2}(2, N=$ $516)=8.54$; CRMSEA $=0.121$, both of which describe the structure of the data less precisely than the full coupling model. Moreover, the other goodness-of-fit indices consistently speak in favor of the model coupling $\gamma_{\text {Speed-Social }}=0$. Hence, on the basis of the estimates from the full coupling model, model comparisons, parsimony, and goodness-of-fit indices, the model implying that level of social participation influences subsequent changes in perceptual speed (model coupling $\gamma_{\text {Speed-Social }}=0$ ) is the preferred model. $^{7}$

To illustrate the implication of these results, we computed the implied sample means from the full coupling and the no coupling models as functions of different initial (t1) values of Speed $(x[1]=$ $39,44,49,54$, or 59$)$ and Social $(x[1]=40,45,50,55$, or 60$)$ at average age and SBS values. In other words, we varied the initial sample estimated means of Speed and Social up and down five units in concert and examined the effects on the expected means from the model allowing for cross-domain couplings (full coupling) and the model not allowing for cross-domain couplings (no coupling). Figure 4 displays the means from the full coupling model (thick lines) and the means from the no coupling model (dashed lines) for Speed (Figure 4A) and Social (Figure 4B). Clearly, these graphs illustrate that allowing for cross-domain lead-lag couplings (i.e., $\gamma_{\text {Social-Speed }}$ and $\gamma_{\text {Speed-Social }}$ ) has profound effects on Speed but negligible effects on Social. Specifically, the implied trajectories for Speed are dramatically different in the full coupling model relative to the no coupling model (Figure 4A) whereas the trajectories for Social do not differ much as a function of the model estimating them (Figure 4B). A closer inspection of Figure $4 \mathrm{~A}$ also facilitates interpretation of the significant and positive $\gamma_{\text {Social-Speed }}$ estimate. For example, the two curves in Figure $4 \mathrm{~A}$ with the highest initial Speed value $(x[1]=59)$ relate to individuals starting out at higher initial levels of Speed and, moreover, to individuals that participate in more social activities. These individuals profit from the effect of social participation; that is, the expected trajectories are more positive in the model allow- ing for cross-domain couplings (full coupling). Analogously, the two curves in Figure 4A with the lowest initial Speed value $(x[1]$ $=39$ ) relate to individuals starting out at lower initial levels of Speed and Social. For these individuals, the lack of social participation is detrimental; that is, the expected trajectories are more negative in the model allowing for cross-domain couplings (full coupling).

\section{Discussion}

This study reveals that within the system of structural relations considered, higher levels of social participation precede and predict 2-year positive deviations from the averaged linear population decline in perceptual speed - an effect more powerful than that of level of perceptual speed on decrease in social participation. Clearly, this result supports the notion that an engaged and active lifestyle in old and very old age may mitigate decline in perceptual speed.

Though these empirical results are clear-cut, we feel obliged to fine-tune the interpretation of the findings. First, the inclusion of very old individuals and the restricted longitudinal observation periods make comparisons to previous studies difficult; that is, the directional dynamics between social participation and perceptual speed may vary across different periods of the life $\operatorname{span}^{8}$ and as a function of the duration of the longitudinal observation period. Second, we stress that the effects of interest reveal something about relatively small deviations from a declining trend. In other words, the significant coupling effect of level of social participation on subsequent 2-year changes in perceptual speed represents an effect on deviations from the mean linear slope. Therefore, the result should be cautiously interpreted as indicating a modifying effect of social participation for decline in perceptual speed rather

\footnotetext{
${ }^{7}$ The parameter estimates from the preferred model coupling $\gamma_{\text {Speed-Social }}=0$ were substantively identical and numerically very close to the estimates from the full coupling model. Therefore, for simplicity, we do not report the estimates from the model coupling $\gamma_{\text {Speed-Social }}=0$.

${ }^{8} \mathrm{We}$ also ran the models separately for the younger half $(n=258$; age range $_{\mathrm{t} 1}=70-84$ years; $\left.M=77.6\right)$ and the older half $(n=258$; age range $_{\mathrm{t} 1}=85-103$ years; $M=92.5$ ) of the sample. In both groups, the analyses produced substantively identical results to those reported here.
} 

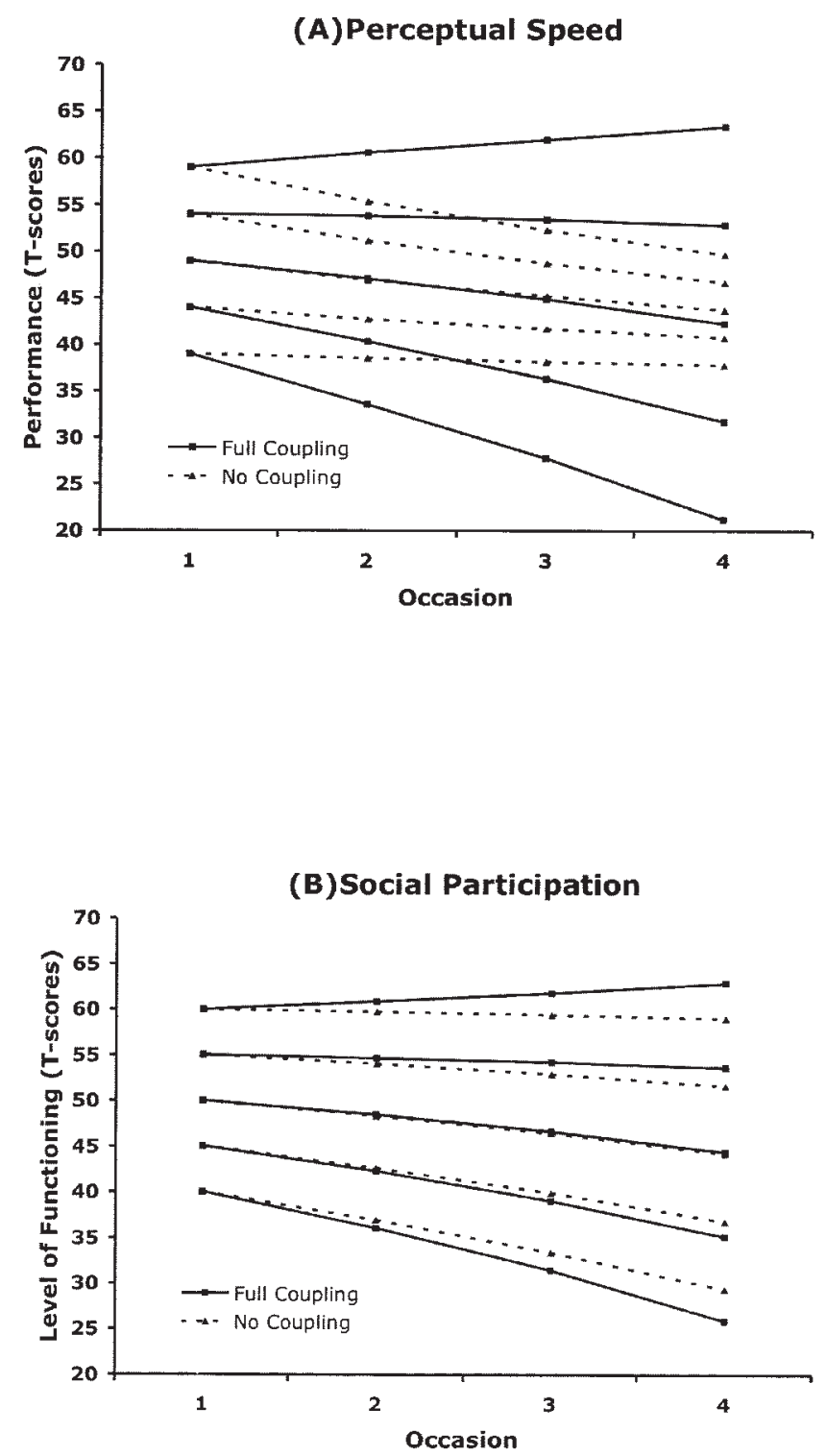

Figure 4. Model implied sample means from the full coupling model (thick lines) and from the no coupling model (dashed lines) for (A) perceptual speed and (B) social participation as a function of time and varied initial (Time 1) sample means $(40,45,50,55$, and 60$)$ of social participation and perceptual speed.

than suggesting that lack of social participation is a primary causal force behind decline or that social participation constitutes a remedy for decline in perceptual speed. Moreover, the aging individual is not accurately described as a bivariate system. Thus, our results may not hold beyond the system considered, which however, included important indicators of aging as well as relevant control variables. Other factors, such as personality (e.g., extraversion) and neurocognitive-influencing disease processes (e.g., depression), may play important roles in the engaged lifestyle-cognition interaction.

Furthermore, we want to underscore that caution is warranted in generalizing the present results to other cognitive abilities. In this article, we chose to focus on perceptual speed because it generally has superior psychometric properties (e.g., reliability) as compared with measures of other cognitive abilities. This enhances the precision of the parameter estimates (Hertzog et al., 2004) and increases the likelihood of model convergence. This seemed especially relevant for the trustworthiness of the results in the context of the relatively limited longitudinal observation period. In addition, perceptual speed has been considered as a central marker of decline in fluid abilities during adulthood and old age (e.g., Lindenberger et al., 1993; Salthouse, 1996; Verhaeghen \& Salthouse, 1997). Thus, perceptual speed is a substantively important ability to examine. However, decline in perceptual speed might be subjectively less salient for the individual than decline in other cognitive abilities, such as episodic memory and knowledge. In other words, decline in some other cognitive ability than perceptual speed might have an impact on engagement in social activities because individuals experience these declines as more immediately limiting their functional capacity.

Little is known about the exact mechanisms by which lifestyle factors such as social participation might influence cognitive decline. An engaged lifestyle might provide greater readiness for compensatory changes in response to neurophysiological decline (e.g., Schaie, 1996; Stern, 2002). These cognitive reserve hypotheses have been proposed in the context of the association between social, mental, and physical stimulation and the incidence of dementia, but other potential mechanisms, such as the vascular and the stress hypotheses, have also been advanced (see Fratiglioni et al., 2004, for review). In other words, lifestyle factors might also modify or protect against potential neurophysiological changes underlying cognitive aging in more direct ways than by introducing interindividual differences in the ability to cope with them. The exact mediating mechanisms might be one or a combination of several alternatives, such as neurophysiological effects of mental stimulations (e.g., environmental complexity and learning) and reduced cardiovascular pathology as an effect of physical activity, which in turn might be associated with social participation. Studies of brain plasticity in rodents and other animals allow for easier categorization of, for example, those effects associated with learning and those associated with exercise (see Churchill et al., 2002, for review).

Of interest, although cognitive plasticity is greatly reduced in very old age (Singer, Lindenberger, \& Baltes, 2003), the aging brain may generate new neurons in response to exercise (e.g., Kemperman, Kuhn, \& Gage, 1998), and enhanced synaptogenesis may occur as a response to environmental complexity (e.g., Greenough, McDonald, Parnisari, \& Camel, 1986). Furthermore, lifestyle factors probably associated with engaged lifestyle and that are related to cognitive performance in old age, such as physical activity (see Colcombe \& Kramer, 2003, for meta-analysis) and nutrition (see Bäckman, Small, Wahlin, \& Larsson, 2000, for review), might be important for reducing age-related negative influences on nonneural components of the brain, such as vascular changes including decreased blood flow, oxygen extraction, and glucose transport (see Churchill et al., 2002, for overview) components of aging not necessarily primarily driven by changes in lifestyle. Thus, to the extent that these mechanisms are associated with cognitive performance and plasticity, an active lifestyle may operate against senescent changes that reduce cognitive plasticity and performance in the first place, or, conversely, lower 
levels of social participation might exacerbate these changes or their functional consequences. Future studies of the lifestylecognition interaction might benefit from a more mechanismoriented approach to resolve these ambiguities in interpretation.

The DCSM constitutes an important advancement over related approaches such as the cross-lagged correlations approach (e.g., Rogosa, 1980a, 1980b) and various SEM approaches that interpret correlations on the basis of latent differences (McArdle \& Nesselroade, 1994) or LGM parameters (Bryk \& Raudenbush, 1987; Meredith \& Tisak, 1990). For example, the DCSM estimates all parameters of an LGM, but the crucial difference is that the DCSM additionally allows the estimation of the time-lagged relations among variables' states and their subsequent changes. Thus, the DCSM allows a glimpse at the directional dynamics within the considered system of variables, and it implements this feature in a more rigorous manner than related approaches such as the crosslagged correlations. For example, the DCSM accounts for differential reliabilities and stabilities of the variables, it partials the intervariable dynamic effects from the intravariable (autoregressive) dynamic effects, and the model analyzes cross-lagged effects among the variables analyzed, while modeling their change. More important though, the model allows for formal empirical comparisons of competing substantive hypotheses. In the present application, this latter feature enabled the conclusion that the model implying that level of social participation influences subsequent changes in perceptual speed (model coupling $\gamma_{\text {Speed-Social }}=0$ ) is the preferred model, whereas the model implying that perceptual speed influences subsequent changes in social participation (model coupling $\gamma_{\text {Social-Speed }}=0$ ) is rejected.

Despite the advantages of the DCSM, it should be highlighted also that results produced by this model are contingent on common statistical assumptions, such as data missing at random (Rubin, 1974), sample homogeneity (Borsboom, Mellenbergh, \& van Heerden, 2003), and the equivalence of structural relations based on interindividual variance and those based on intraindividual variance (Molenaar, Huizenga, \& Nesselroade, 2003)—assumptions for which the tenability is at best unknown. Note also that limited amounts of methodological work have specifically targeted the unique features of the DCSM. Recent work by Hertzog and colleagues (2004) on the related LGM shows that the power to detect variances and covariances is surprisingly low with typical data sets from longitudinal studies on cognitive aging, containing relatively few assessments and moderately reliable measures (see also Willett, 1989). In other words, the precision of the estimates from these models is at times relatively unsatisfactory. Although generalizing these results to the DCSM is not straightforward, we note a correspondence in that the estimates of the covariances involving the slope factors were unstable in the present application. As noted in the Results section, the unstable covariances do not affect the stability of the other parameter estimates in the model (see also Ghisletta \& Lindenberger, 2003; Hamagami \& McArdle, 2001; McArdle et al., 2004). Especially comforting in the context of the competing hypotheses in this study is that the standard errors of the two cross-lagged coupling parameters are of similar size (see Table 3). Thus, there is no differential power issue operating in favor of finding an effect of social participation on perceptual speed.

To sum up, even in the face of the discussed limitations, the empirical results reported in this study are difficult to ignore:
Within the system considered, higher values of social participation predict subsequent positive 2-year deviations from the averaged linear decline in perceptual speed, whereas values of perceptual speed do not influence subsequent latent changes in social participation. Therefore, we conclude that the empirical evidence to date suggests that an engaged and active lifestyle in old and very old age may alleviate decline in perceptual speed.

\section{References}

Aartsen, M. J., Smits, C. H. M., van Tilburg, T., Knipscheer, K. C. P. M., \& Deeg, D. J. H. (2002). Activity in older adults: Cause or consequence of cognitive functioning? A longitudinal study on everyday activities and cognitive performance in older adults. Journal of Gerontology: Psychological Sciences, 57B, P153-P162.

Albert, M. S., Jones, K., Savage, C. R., Berkman, L., Seeman, T., Blazer, D., \& Rowe, J. W. (1995). Predictors of cognitive change in older persons: MacArthur studies of successful aging. Psychology and Aging, $10,578-589$.

Arbuckle, J. L. (1996). Full information estimation in the presence of incomplete data. In G. A. Marcoulides \& R. E. Schumacker (Eds.), Advanced structural equation modeling: Issues and techniques (pp. 243-277). Mahwah, NJ: Erlbaum.

Arbuckle, J. L., \& Wothke, W. (1999). Amos 4.0 user's guide. Chicago: Smallwaters.

Arbuckle, T. Y., Gold, D. P., \& Andres, D. (1986). Cognitive functioning of older people in relation to social and personality variables. Psychology and Aging, 1, 55-62.

Bäckman, L., Small, B. J., Wahlin, A., \& Larsson, M. (2000). Cognitive functioning in very old age. In F. I. M. Craik \& T. A. Salthouse (Eds.), The handbook of aging and cognition (2nd ed., pp. 499-558). Mahwah, NJ: Erlbaum.

Baltes, M. M., Maas, I., Wilms, H.-U., Borchelt, M., \& Little, T. D. (1999). Everyday competence in old and very old age: Theoretical considerations and empirical findings. In P. B. Baltes \& K. U. Mayer (Eds.), The Berlin Aging Study: Aging from 70 to 100 (pp. 384-403). Cambridge, England: Cambridge University Press.

Baltes, P. B., Lindenberger, U., \& Staudinger, U. M. (in press). Lifespan theory in developmental psychology. In R. M. Lerner (Ed.), Handbook of child psychology: Vol. 1. Theoretical models of human development (6th ed.). New York: Wiley.

Baltes, P. B., \& Mayer, K. U. (Eds.). (1999). The Berlin Aging Study: Aging from 70 to 100. Cambridge, England: Cambridge University Press.

Borsboom, D., Mellenbergh, G. J., \& van Heerden, J. (2003). The theoretical status of latent variables. Psychological Review, 90, 105-126.

Bosma, H., van Boxtel, M. P. J., Ponds, R. W. H. M., Jelicic, M., Houx, P., Metsemakers, J., \& Jolles, J. (2002). Engaged lifestyle and cognitive function in middle and old-aged, non-demented persons: A reciprocal association? Zeitschrift für Gerontologie and Geriatrie, 35, 575-581.

Browne, M., \& Cudeck, R. (1993). Alternative ways of assessing model fit. In K. A. Boolen \& J. S. Long (Eds.), Testing structural equation models (pp. 136-162). Newbury Park, CA: Sage.

Browne, M., \& DuToit, S. H. C. (1992). Automated fitting of nonstandard models. Multivariate Behavioral Research, 27, 269-300.

Bryk, A. S., \& Raudenbush, S. W. (1987). Application of hierarchical linear models to assessing change. Psychological Bulletin, 101, 147158.

Bukov, A., Maas, I., \& Lampert, T. (2002). Social participation in very old age: Cross-sectional and longitudinal findings from BASE. Journal of Gerontology: Psychological Sciences, 57B, P510-P517.

Churchill, J. D., Galvez, R., Colcombe, S., Swain, R. A., Kramer, A. F., \& Greenough, W. T. (2002). Exercise, experience and the aging brain. Neurobiology of Aging, 23, 941-955. 
Cohen, J. (1988). Statistical power analysis for the behavioural sciences (2nd ed.). New York: Academic Press.

Colcombe, S., \& Kramer, A. F. (2003). Fitness effects on the cognitive function of older adults: A meta-analytic study. Psychological Science, $14,125-130$.

Craik, F. I. M., Byrd, M., \& Swanson, J. M. (1987). Patterns of memory loss in three elderly samples. Psychology and Aging, 2, 79-86.

Ekstrom, R. B., French, J. W., Harman, H. H., \& Derman, D. (1976). Manual for kit of factor-referenced cognitive tests. Princeton, NJ: Educational Testing Service.

Fratiglioni, L., Paillard-Borg, S., \& Winblad, B. (2004). An active and socially integrated lifestyle in late life might protect against dementia. Lancet Neurology, 3, 343-353.

Ghisletta, P., \& Lindenberger, U. (2003). Age-based structural dynamics between perceptual speed and knowledge in the Berlin Aging Study: Direct evidence for ability dedifferentiation in old age. Psychology and Aging, 18, 696-713.

Greenough, W. T., McDonald, J. W., Parnisari, R. M., \& Camel, J. E. (1986). Environmental conditions modulate degeneration and new dendrite growth in cerebellum of senescent rat. Brain Research, 380, 136143

Hamagami, F., \& McArdle, J. J. (2001). Advanced studies of individual differences linear dynamic models for longitudinal data analysis. In G. Marcoulides \& R. Schumacker (Eds.), New developments and techniques in structural equation modeling (pp. 203-246). Mahwah, NJ: Erlbaum.

Hertzog, C., Hultsch, D. F., \& Dixon, R. A. (1999). On the problem of detecting effects of lifestyle on cognitive change in adulthood: Reply to Pushkar et al. (1999). Psychology and Aging, 14, 528-534.

Hertzog, C., Lindenberger, U., Ghisletta, P., \& von Oertzen, T. (2004). On the power of multivariate latent growth curve models to detect individual differences in change. Manuscript submitted for publication.

Hultsch, D. F., Hertzog, C., Small, B. J., \& Dixon, R. A. (1999). Use it or lose it: Engaged lifestyle as a buffer of cognitive decline in aging? Psychology and Aging, 14, 245-263.

Katz, S., Ford, A. B., Moskowitz, R. W., Jackson, B. A., \& Jaffe, M. W. (1963). Studies of illness in the aged. The index of ADL: A standardized measure of biological and psychosocial function. Journal of the American Medical Association, 185, 914-919.

Kemperman, G., Kuhn, H. G., \& Gage, F. H. (1998). Experience-induced neurogenesis in the senescent dentate gyrus. Journal of Neuroscience, $18,3206-3212$.

Kline, R. B. (1998). Principles and practice of structural equation modeling. New York: Guilford Press.

Lawton, M. P., \& Brody, E. M. (1969). Assessment of older people: Self-maintaining and instrumental activities of daily living. The Gerontologist, 9, 179-186.

Li, S.-C. (2003). Biocultural orchestration of developmental plasticity across levels: The interplay of biology and culture in shaping the mind and behavior across the life span. Psychological Bulletin, 129, 171-194.

Lindenberger, U., Gilberg, R., Little., T. D., Nuthman, R., Pötter, U., \& Baltes, P. B. (1999). Sample selectivity and generalizability of the results of the Berlin Aging Study. In P. B. Baltes \& K. U. Mayer (Eds.), The Berlin Aging Study: Aging from 70 to 100 (pp. 56-83). Cambridge, England: Cambridge University Press.

Lindenberger, U., Mayr, U., \& Kliegl, R. (1993). Speed and intelligence in old age. Psychology and Aging, 8, 207-220.

Lindenberger, U., Singer, T., \& Baltes, P. B. (2002). Longitudinal selectivity in aging populations: Separating mortality-associated versus experimental components in the Berlin Aging Study (BASE). Journal of Gerontology: Psychological Sciences, 57B, P474-P482.

Lövdén, M., \& Lindenberger, U. (2005). Development of intellectual abilities in old age: From age gradients to individuals. In O. Wilhelm \&
R. Engle (Eds.), Understanding and measuring intelligence (pp. $203-$ 221). Thousand Oaks, CA: Sage.

Mackinnon, A., Christensen, H., Hofer, S. M., Korten, A. E., \& Jorm, A. F. (2003). Use it and still lose it? The association between activity and cognitive performance established using latent growth techniques in a community sample. Aging, Neuropsychology, \& Cognition, 10, 215229.

Mayer, K. U., Maas, I., \& Wagner, M. (1999). Socioeconomic conditions and social inequalities in old age. In P. B. Baltes \& K. U. Mayer (Eds.), The Berlin Aging Study: Aging from 70 to 100 (pp. 227-259). Cambridge, England: Cambridge University Press.

McArdle, J. J. (2001). A latent difference score approach to longitudinal dynamic structural equation analyses. In R. Cudeck, S. duToit, \& D. Sörbom (Eds.), Structural equation modeling: Present and future (pp. 342-380). Lincolnwood, IL: Scientific Software International.

McArdle, J. J., \& Hamagami, F. (2001). Latent difference score structural models for linear dynamic analyses with incomplete longitudinal data. In L. M. Collins \& A. G. Sayer (Eds.), New methods for the analysis of change (pp. 139-175). Washington, DC: American Psychological Association.

McArdle, J. J., \& Hamagami, F. (in press). Longitudinal structural equation modeling methods for dynamic change hypotheses. In K. van Montfort (Ed.), Structural equation models and related topics. Tilburg, The Netherlands; University of Tilburg.

McArdle, J. J., Hamagami, F., Jones, K., Jolesz, F., Kikinis, R., Spiro, A., \& Albert, M. S. (2004). Structural modeling of dynamic changes in memory and brain structure using longitudinal data from the normative aging study. Journal of Gerontology: Psychological Sciences, 59B, 294-304

McArdle, J. J., \& Nesselroade, J. R. (1994). Using multivariate data to structure developmental change. In S. H. Cohen \& H. W. Reese (Eds.), Life-span developmental psychology: Methodological contributions (pp. 223-267). Hillsdale, NJ: Erlbaum.

Meredith, W., \& Tisak, J. (1990). Latent curve analysis. Psychometrica, 55, 107-122.

Molenaar, P. C. M., Huizenga, H. M., \& Nesselroade, J. R. (2003). The relationship between the structure of interindividual and intraindividual variability: A theoretical and empirical vindication of developmental systems theory. In U. M. Staudinger \& U. Lindenberger (Eds.), Understanding human development: Dialogues with lifespan psychology (pp. 339-360). Dordrecht, the Netherlands: Kluwer Academic.

Moss, M., \& Lawton, M. P. (1982). Time budgets of older people: A window on four lifestyles. Journal of Gerontology, 37, 576-582.

Neale, M. C., Boker, S. C., Xie, G., \& Maes, H. H. (1999). Mx: Statistical modeling [Computer software] (5th ed.). Richmond: Medical College of Virginia.

Nesselroade, J. R. (2002). Elaborating the differential in differential psychology. Multivariate Behavioral Research, 37, 543-561.

Pushkar, D., Etezadi, J., Andres, D., Arbuckle, T., Schwartzmann, A. E., \& Chaikelson, J. (1999). Models of intelligence in late life: Comment on Hultsch et al. (1999). Psychology and Aging, 14, 520-527.

Rogosa, D. (1980a). Comparison of some procedures for analyzing longitudinal panel data. Journal of Economics and Business, 32, 136-151.

Rogosa, D. (1980b). A critique of cross-lagged correlations. Psychological Bulletin, 88, 245-258.

Rubin, D. (1974). Characterizing the estimation of parameters in incomplete-data problems. Journal of American Statistical Association, 69, 467-474.

Salthouse, T. A. (1991). Theoretical perspectives on cognitive aging. Hillsdale, NJ: Erlbaum.

Salthouse, T. A. (1996). The processing speed theory of adult age differences in cognition. Psychological Review, 103, 403-428.

Salthouse, T. A., Berish, D. E., \& Miles, J. D. (2002). The role of cognitive 
stimulation on the relations between age and cognitive functioning. Psychology and Aging, 17, 548-557.

Schaie, K. W. (1996). Intellectual development in adulthood: The Seattle Longitudinal Study. New York: Cambridge University Press.

Schooler, C., \& Mulatu, M. S. (2001). The reciprocal effects of leisure time activities and intellectual functioning in older people: A longitudinal analysis. Psychology and Aging, 16, 466-482.

Singer, T., Lindenberger, U., \& Baltes, P. B. (2003). Plasticity of memory for new learning in very old age: A story of major loss? Psychology and Aging, 18, 306-317.

Steiger, J. H., \& Lind, J. M. (1980, June). Statistically-based tests for the number of common factors. Paper presented at the annual meeting of the Psychometric Society, Iowa City, IA.

Stern, Y. (2002). What is cognitive reserve? Theory and research application of the reserve concept. Journal of the International Neuropsychological Society, 8, 448-460.
Verhaeghen, P., \& Salthouse, T. A. (1997). Meta-analyses of age-cognition relations in adulthood: Estimates of linear and nonlinear age effects and structural models. Psychological Bulletin, 122, 231-249.

Willett, J. B. (1989). Some results on reliability for the measurement of change: Implications for the design of studies of individual growth. Educational and Psychological Measurement, 49, 587-602.

Wothke, W. (2000). Longitudinal and multi-group modeling with missing data. In T. D. Little, K. U. Schnabel, \& J. Baumert (Eds.), Modeling longitudinal and multilevel data: Practical issues, applied approaches, and specific examples (pp. 1-24). Mahwah, NJ: Erlbaum.

Received March 24, 2004

Revision received March 11, 2005

Accepted May 3, 2005

\section{Members of Underrepresented Groups: Reviewers for Journal Manuscripts Wanted}

If you are interested in reviewing manuscripts for APA journals, the APA Publications and Communications Board would like to invite your participation. Manuscript reviewers are vital to the publications process. As a reviewer, you would gain valuable experience in publishing. The $\mathrm{P} \& \mathrm{C}$ Board is particularly interested in encouraging members of underrepresented groups to participate more in this process.

If you are interested in reviewing manuscripts, please write to Demarie Jackson at the address below. Please note the following important points:

- To be selected as a reviewer, you must have published articles in peer-reviewed journals. The experience of publishing provides a reviewer with the basis for preparing a thorough, objective review.

- To be selected, it is critical to be a regular reader of the five to six empirical journals that are most central to the area or journal for which you would like to review. Current knowledge of recently published research provides a reviewer with the knowledge base to evaluate a new submission within the context of existing research.

- To select the appropriate reviewers for each manuscript, the editor needs detailed information. Please include with your letter your vita. In your letter, please identify which APA journal(s) you are interested in, and describe your area of expertise. Be as specific as possible. For example, "social psychology" is not sufficient-you would need to specify "social cognition" or "attitude change" as well.

- Reviewing a manuscript takes time (1-4 hours per manuscript reviewed). If you are selected to review a manuscript, be prepared to invest the necessary time to evaluate the manuscript thoroughly.

Write to Demarie Jackson, Journals Office, American Psychological Association, 750 First Street, NE, Washington, DC 20002-4242. 